\title{
Lifestyle and impact on cardiovascular risk factor control in coronary patients across 27 countries: Results from the European Society of Cardiology ESC-EORP EUROASPIRE V registry
}

European Journal of Preventive Cardiology

Kornelia Kotseva',2, Guy De Backer ${ }^{1,3}$, Dirk De Bacquer ${ }^{1,3}$, Lars Rydén $^{1,4}$, Arno Hoes ${ }^{1,5}$, Diederick Grobbee ${ }^{1,6}$, Aldo Maggioni ${ }^{1,7}$, Pedro Marques-Vidal ${ }^{1,8}$, Catriona Jennings ${ }^{1,2}$, Ana Abreu9, Carlos Aguiar ${ }^{1,10}$, Jolita Badariene ${ }^{11,12}$, Jan Bruthans ${ }^{1,13}$, Almudena Castro Conde ${ }^{14}$, Renata Cifkova ',13, Jim Crowley ${ }^{1,15}$, Kairat Davletov ${ }^{16}$, Jaap Deckers ${ }^{1,17}$, Delphine De Smedt ${ }^{1,3}$, Johan De Sutter ${ }^{1,18,19}$, Mirza Dilic ${ }^{1,20}$, Marina Dolzhenko ${ }^{21}$, Vilnis Dzerve ${ }^{1,22}$, Andrejs Erglis ${ }^{1,23}$, Zlatko Fras ${ }^{1,24,25}$, Dan Gaita ${ }^{1,26}$, Nina Gotcheva ${ }^{27}$, Peter Heuschmann ${ }^{28,29,30}$, Hosam Hasan-Ali ${ }^{31}$, Piotr Jankowski ${ }^{32}$, Nebojsa Lalic ${ }^{33}$, Seppo Lehto ${ }^{1,34}$, Dragan Lovic ${ }^{1,35}$, Silvia Mancas ${ }^{26}$, Linda Mellbin 1,4, Davor Milicic ${ }^{1,36}$, Erkin Mirrakhimov'1,37,38, Rafael Oganov ${ }^{39}$, Nana Pogosova ${ }^{40}$, Zeljko Reiner ${ }^{1,41}$, Stefan Stöerk $^{30,42}$, Lâle Tokgözoğlu ${ }^{1,43}$, Costas Tsioufis ${ }^{1,44}$, Dusko Vulic $^{45}$ and David Wood ${ }^{1,2,46}$; on behalf of the EUROASPIRE Investigators*

\footnotetext{
'European Society of Cardiology, Sophia Antipolis, France

${ }^{2}$ National Heart and Lung Institute, Imperial College London, UK

${ }^{3}$ Department of Public Health and Primary Care, Ghent University, Belgium

${ }^{4}$ Department of Medicine Solna, Karolinska Institutet, Stockholm, Sweden

${ }^{5}$ Julius Centre for Health Sciences and Primary Care, University Medical Centre Utrecht, The Netherlands

6 Julius Global Health, Julius Centre for Health Sciences and Primary Care, University Medical Centre Utrecht, The Netherlands

${ }^{7}$ ANMCO Research Centre, Florence, Italy

${ }^{8}$ Department of Medicine, Internal Medicine, Lausanne University Hospital, Switzerland

${ }^{9}$ Hospital Santa Marta, Centro Hospitalar de Lisboa Central, Lisbon, Portugal

${ }^{10}$ Hospital Santa Cruz, Centro Hospitalar de Lisboa Ocidental, Lisbon, Portugal

"Clinic of Cardiac and Vascular diseases, Medical Faculty, Vilnius University, Lithuania

${ }^{12}$ Centre of Cardiology and Angiology, Vilnius University Hospital Santaros Klinikos, Lithuania

${ }^{13}$ Centre for Cardiovascular Prevention, Charles University in Prague, First Faculty of Medicine and Thomayer Hospital, Czech Republic
}

\footnotetext{
${ }^{14}$ Cardiac Rehabilitation Unit, Cardiology Department, Hospital Universitario La Paz, Madrid, Spain

${ }^{15}$ Department of Cardiology, Galway University Hospital and Croí, the West of Ireland Cardiac and Stroke Foundation, Croí Heart and Stroke Centre, Galway, Ireland

${ }^{16}$ School of Public Health, Public Health Research Centre, Kazakh National Medical University, Almaty, Kazakhstan

${ }^{17}$ Erasmus MC, Rotterdam, The Netherlands

${ }^{18}$ Department of Internal Medicine and Paediatrics, Ghent University, Belgium

${ }^{19} \mathrm{AZ}$ Maria Middelares Ghent, Belgium

${ }^{20}$ Medical Faculty, University of Sarajevo, Bosnia and Herzegovina

${ }^{21}$ Supyk National Medical Academy of Postgraduate Education, Kiev, Ukraine

${ }^{22}$ Institute of Cardiology and Regenerative Medicine, University of Latvia, Riga, Latvia

${ }^{23}$ Pauls Stradins Clinical University Hospita, University of Latvia, Riga, Latvia

Corresponding author:

Kornelia Kotseva, National Heart \& Lung Institute, Imperial College London, Emmanuel Kaye Building, Royal Brompton Hospital Campus, Ib Manresa Road, London SW3 6LR, UK.

Email: k.kotseva@imperial.ac.uk
} 


\begin{abstract}
Aims: The aim of this study was to determine whether the Joint European Societies guidelines on secondary cardiovascular prevention are followed in everyday practice.

Design: A cross-sectional ESC-EORP survey (EUROASPIRE V) at $|3|$ centres in $8 \mid$ regions in 27 countries.

Methods: Patients ( $<80$ years old) with verified coronary artery events or interventions were interviewed and examined $\geq 6$ months later.

Results: A total of $826 \mathrm{I}$ patients (females $26 \%$ ) were interviewed. Nineteen per cent smoked and $55 \%$ of them were persistent smokers, $38 \%$ were obese (body mass index $\geq 30 \mathrm{~kg} / \mathrm{m}^{2}$ ), $59 \%$ were centrally obese (waist circumference: men $\geq 102 \mathrm{~cm}$; women $\geq 88 \mathrm{~cm}$ ) while $66 \%$ were physically active $<30 \mathrm{~min} 5$ times/week. Forty-two per cent had a blood pressure $\geq 140 / 90 \mathrm{mmHg}$ ( $\geq 140 / 85$ if diabetic), $71 \%$ had low-density lipoprotein cholesterol $\geq 1.8 \mathrm{mmol} / \mathrm{L}(\geq 70 \mathrm{mg} / \mathrm{dL})$ and $29 \%$ reported having diabetes. Cardioprotective medication was: anti-platelets $93 \%$, beta-blockers $81 \%$, angiotensinconverting enzyme inhibitors/angiotensin receptor blockers $75 \%$ and statins $80 \%$.

Conclusion: A large majority of coronary patients have unhealthy lifestyles in terms of smoking, diet and sedentary behaviour, which adversely impacts major cardiovascular risk factors. A majority did not achieve their blood pressure, low-density lipoprotein cholesterol and glucose targets. Cardiovascular prevention requires modern preventive cardiology programmes delivered by interdisciplinary teams of healthcare professionals addressing all aspects of lifestyle and risk factor management, in order to reduce the risk of recurrent cardiovascular events.
\end{abstract}

\title{
Keywords \\ EUROASPIRE, lifestyle, cardiovascular risk factors, secondary prevention, guidelines
}

Received 17 November 2018; accepted 28 December 2018

\section{Introduction}

The main objectives of cardiovascular disease (CVD) prevention are to prevent premature morbidity and mortality, improve quality of life and reduce increasing healthcare costs. ${ }^{1-6}$ CVD remains a leading cause of death across Europe with about $44 \%$ of the deaths related to coronary heart disease $(\mathrm{CHD}) .^{7}$ The European Society of Cardiology (ESC), together with other partners, has engaged in a comprehensive programme of CVD prevention in clinical practice for almost 25 years. Joint European Societies (JES)

\footnotetext{
${ }^{24}$ Preventive Cardiology Unit, Department of Vascular Medicine, Division of Medicine, University Medical Centre Ljubljana, Ljubljana, Slovenia ${ }^{25}$ Medical Faculty, University of Ljubljana, Slovenia

${ }^{26}$ Universitatea de Medicina si Farmacie Victor Babes, Institutul de Boli

Cardiovasculare, Clinica de Recuperare Cardiovasculara, Timisoara,

Romania

${ }^{27}$ National Heart Hospital, Dept Cardiology, Sofia, Bulgaria

${ }^{28}$ Institute of Clinical Epidemiology and Biometry, University of Würzburg, Germany

${ }^{29}$ Clinical Trial Centre, University Hospital Würzburg, Germany

${ }^{30}$ Comprehensive Heart Failure Centre, University and University Hospital Würzburg, Germany

${ }^{31}$ Assiut University Heart Hospital, Cardiovascular Medicine

Department, Egypt

${ }^{32}$ Department of Cardiology, Interventional Electrocardiology and Hypertension, Jagiellonian University Medical College, Krakow, Poland

${ }^{33}$ Department for Metabolic Disorder, Intensive Treatment and Cell

Therapy in Diabetes, Clinic for Endocrinology, Diabetes and Metabolic

Diseases, Clinical Centre of Serbia, Belgrade, Serbia

${ }^{34}$ Varkaus Hospital, Finland
}

recommendations, first published in 1994, have been updated five times, most recently in $2016,{ }^{1-6}$ with the aim to promote evidence-based preventive cardiology by encouraging national guidance on CVD prevention and its communication, implementation and regular audit. Implementation of these guidelines has been repeatedly evaluated by the EUROASPIRE (European Action on Secondary and Primary Prevention by

\footnotetext{
${ }^{35}$ Clinic for Internal Disease Intermedic, Cardiology Department, Hypertension Centre, Nis, Serbia

${ }^{36}$ University of Zagreb School of Medicine \& University Hospital Centre Zagreb, Croatia

${ }^{37}$ Kyrgyz State Medical Academy, Bishkek, Kyrgyzstan

${ }^{38}$ National Centre of Cardiology and Internal Medicine named after academician Mirrakhimov MM, Bishkek, Kyrgyzstan

${ }^{39}$ National Research Centre for Preventive Medicine, Directorate, Moscow, Russia

${ }^{40}$ Federal State Budget Organization, National Medical Research Centre of Cardiology of the Ministry of Healthcare of the Russian Federation, Moscow, Russia

${ }^{41}$ University Hospital Centre Zagreb, School of Medicine, University of Zagreb, Croatia

${ }^{42}$ Department of Medicine I, University Hospital Würzburg, Germany

${ }^{43}$ Department of Cardiology, Hacettepe University, Ankara, Turkey

${ }^{44}$ First Department of Cardiology, Medical School, National and

Kapodistrian University of Athens, Greece

${ }^{45}$ Centre for Medical Research, School of Medicine, University of Banja

Luka, Republic of Srpska, Bosnia and Herzegovina

${ }^{46}$ National University of Ireland, Galway, Ireland

* Listed in Supplemental Appendix
} 
Intervention to Reduce Events) surveys. ${ }^{8-15}$ The fourth and fifth EUROASPIRE surveys merged with the EuroHeart Survey on Diabetes. ${ }^{13,14,16,17}$ From 2012 EUROASPIRE has been part of the EURObservational Research Programme (EORP) of the ESC.

EUROASPIRE V was performed to identify risk factors in coronary patients with and without diabetes, describe their management through lifestyle modifications and use of drug therapies in order to provide an objective assessment of the implementation of current evidencebased CVD prevention. This report focuses on lifestyle adaptation and the control of blood pressure, low-density lipoprotein cholesterol (LDL-C) and diabetes.

\section{Study population and methods}

\section{Geographical area and hospital sampling frame}

EUROASPIRE V is a cross-sectional study carried out in 2016-2017 in 27 countries as listed in the Supplementary Material Table 1 online. At least one geographical area with a defined population was selected within each country and their serving hospitals (a minimum of two) identified in order to provide any patient with acute coronary symptoms, or requiring revascularization (percutaneous coronary intervention (PCI) or coronary artery bypass surgery (CABG), with a similar chance of being included.

Consecutive patients ( $\geq 18$ to $<80$ years old) were identified from diagnostic registers, hospital discharge lists or other sources with a first or recurrent clinical diagnosis or treatment of (i) elective or emergency CABG, (ii) elective or emergency PCI, (iii) acute myocardial infarction (ICD-10 I21) and (iv) acute myocardial ischaemia (ICD-10 I20). The starting date for identification was $\geq 6$ months to $<2$ years prior to date of study interview. Eligible patients were invited to attend a study visit. The invitation procedure varied between countries, depending on local data protection rules.

\section{Data collection and definitions}

The ESC EUROASPIRE V registry conducted by EURObservational Research Programme (EORP) is a cross-sectional survey performed in 131 centres in 81 regions in 27 countries within the European Society of Cardiology. Data collection was undertaken by centrally trained research staff, who, within the stated time window, reviewed patient medical records and interviewed and examined the patients using standardized methods and similar instruments at all centres. Information on personal and demographic details, smoking status, history of obesity, hypertension, dyslipidaemia, glucose metabolism and medication was obtained from medical records. Self-reported information on lifestyle, other risk factor management and medication was obtained at interview. The selfreported questionnaires were all validated versions for each country. The following measurements were performed:

Smoking at the time of interview was defined as selfreported smoking and/or a breath carbon monoxide exceeding $10 \mathrm{ppm}^{18}$ by means of Smokerlyzer ${ }^{\circledR}$ (Bedfont Scientific, Model Micro+). Persistent smoking was defined as smoking at time of interview among those who smoked in the month prior to the index event.

Height and weight were measured in light indoor clothes without shoes (SECA scales 701 and measuring stick model 220). Overweight was defined as a body mass index $(\mathrm{BMI}) \geq 25$ to $<30 \mathrm{~kg} / \mathrm{m}^{2}$ and obesity as BMI $\geq 30 \mathrm{~kg} / \mathrm{m}^{2}$.

Waist circumference was measured using a metal tape horizontally in the mid-axillary line midway between the lowest rim of the rib cage and tip of the hip bone with the patient standing. ${ }^{19}$ Abdominal overweight was defined as a waist circumference of $\geq 80$ to $<88 \mathrm{~cm}$ for women and $\geq 94$ to $<102 \mathrm{~cm}$ for men and central obesity as a waist circumference of $\geq 88 \mathrm{~cm}$ for women and $\geq 102 \mathrm{~cm}$ for men.

The physical activity target was defined by the following question: "Do you take regular physical activity of at least 30 minutes' duration on average five times a week?"

Blood pressure was measured twice on the right upper arm in a sitting position using an automatic digital sphygmomanometer (Omron M6). The mean was used for analysis with raised blood pressure defined as $\geq 140 / 90 \mathrm{mmHg}$ ( $\geq 140 / 85 \mathrm{mmHg}$ if diabetes).

Venous (fasting) blood was drawn for serum total and high-density lipoprotein cholesterol (HDL-C), triglycerides and glycated haemoglobin (HbAlc). The LDL-C was calculated by Friedewald's formula. ${ }^{20}$ Elevated LDL-C concentration was defined as $\geq 1.8 \mathrm{mmol} / \mathrm{L}(\geq 70 \mathrm{mg} / \mathrm{dL})$. Plasma glucose was analysed locally with a point-of-care technique (Glucose 201RT, HemoCue ${ }^{\circledR}$, Ängelholm, Sweden). ${ }^{21}$ Elevated fasting glucose among patients with diabetes was defined as $\geq 6.0 \mathrm{mmol} / \mathrm{L}(\geq 110 \mathrm{mg} / \mathrm{dL})$ and elevated HbAlc as $\geq 7.0 \%$ (International Federation of Clinical Chemistry (IFCC) $\geq 53 \mathrm{mmol} / \mathrm{mol}$ ).

The Laboratory in the National Institute for Health and Welfare (Helsinki, Finland), accredited by the Finnish Accreditation Service and fulfilling requirements of the standard SFS-EN ISO/IEC 17025:2005, acted as the central laboratory. Venous blood was taken into a tube containing clot activator (Vacutainer SST II Advanced, Becton Dickinson) for lipid assays and into a potassium EDTA tube (Vacutainer K2EDTA) for HbA1c assay. Samples were stored locally at $-70^{\circ} \mathrm{C}$. All measurements were performed on a clinical chemistry analyser (Architect c8000; Abbott 
Laboratories, Abbott Park, Illinois, USA). Total cholesterol, HDL-C, creatinine and triglycerides were analysed in serum, and HbAlc in whole blood.

\section{Data management}

Electronically collected data were submitted online to the data management centre (EURObservational Research Program (EORP), ESC, Sophia-Antipolis, France).

\section{Statistical analyses}

Overall, sample size calculations indicated that groups of 400 patients were sufficient to produce prevalence estimates with a precision of at least $5 \%$ with $95 \%$ confidence. Descriptive statistics were used to estimate the prevalence of risk factors and medication use at interview. Patients' demographics, risk factor profiles and use of medication were described according to means, standard deviations and proportions. Relevant comparisons of risk factor prevalences were evaluated according to mixed logistic regression analyses accounting for clustering of patients within countries and with additional adjustment for age and gender. All analyses were undertaken using SAS statistical software (release 9.4) in the Department of Public Health, Ghent University, Belgium.

Ethical procedures. National Co-ordinators were responsible for obtaining Local Ethics Committees approvals. Written, informed consent was obtained from each participant and stored in the patient file.

Outcome measures. The main outcome measures were the proportions of coronary patients achieving the lifestyle, risk factor and therapeutic targets as defined in the 2016 guidelines on CVD prevention. ${ }^{6}$

\section{Results}

The survey was undertaken at 131 centres covering 81 geographical regions in 27 countries: Belgium, Bosnia \& Herzegovina, Bulgaria, Croatia, Czech Republic, Egypt, Finland, Germany, Greece, Ireland, Italy, Kazakhstan, Kyrgyzstan, Latvia, Lithuania, The Netherlands, Poland, Portugal, Romania, Russia, Serbia, Slovenia, Spain, Sweden, Turkey, Ukraine and the UK. A total of 16,208 medical records were reviewed and 8261 patients attended the interview with a participation rate (excluding patients who died, moved away or had a change in medical condition) of $56 \%$. Supplementary Table 1 lists the countries, geographical regions and numbers of patients attending interview.

The median time between the index event and the interview was 1.1 years (interquartile range 0.8-1.6). The reasons for not being interviewed were: no response to the invitation letter $56 \%$, refusal to attend for personal reasons $38 \%$, miscellaneous $6 \%$. Patient characteristics at interview are presented in Table 1. Overall, the mean (SD) age at interview was 64 (10) years and 26\% were women. Following their index event $78 \%$ were under care of a cardiologist and/or a general practitioner (57\%), a diabetologist/ endocrinologist (11\%) and/or a specialist cardiac nurse $(4 \%)$, with wide variation between countries.

\section{Smoking, body weight and physical activity}

Results on smoking, overweight and obesity and physical activity are shown in Table 2. The overall prevalence of smoking at time of interview was $19 \%$

Table I. Patients' characteristics at interview.

\begin{tabular}{|c|c|c|c|}
\hline Characteristics & $\begin{array}{l}\text { All } \\
N=826 I\end{array}$ & $\begin{array}{l}\text { Men } \\
n=6132\end{array}$ & $\begin{array}{l}\text { Women } \\
n=2129\end{array}$ \\
\hline Age, mean (SD) & $63.6(9.6)$ & $63.0(9.7)$ & $65.4(9.2)$ \\
\hline$<50$ years, \% $(n)$ & $9.3(772)$ & $10.3(630)$ & $6.7(142)$ \\
\hline $50-59$ years, \% (n) & $24.7(2043)$ & $26.4(1619)$ & $19.9(424)$ \\
\hline $60-69$ years, \% (n) & $38.1(3150)$ & $38.0(2330)$ & $38.5(820)$ \\
\hline$\geq 70$ years, $\%(n)$ & $27.8(2296)$ & $25.3(1553)$ & $34.9(743)$ \\
\hline \multicolumn{4}{|l|}{ Medical history } \\
\hline Hospitalization for CABG, \% (n) & $18.6(1535)$ & $20.4(1253)$ & $13.2(282)$ \\
\hline $\mathrm{PCl}, \%(n)$ & $80.2(6629)$ & $82.1(5035)$ & $74.9(1594)$ \\
\hline ACS without revascularization, \% (n) & II.I (919) & $8.4(516)$ & $18.9(403)$ \\
\hline Stroke, \% (n) & $4.1(34 I)$ & $3.7(229)$ & $5.3(I \mid 2)$ \\
\hline Peripheral artery disease, $\%(n)$ & $2.7(221)$ & $2.7(167)$ & $2.5(54)$ \\
\hline
\end{tabular}

CABG: coronary artery bypass graft surgery; PCl: percutaneous coronary intervention; ACS: acute coronary syndrome 
Table 2. Patients' lifestyles at the time of interview.

\begin{tabular}{|c|c|c|c|c|c|}
\hline \multirow[b]{2}{*}{ Lifestyle characteristics } & \multirow[b]{2}{*}{$\begin{array}{l}\text { All } \\
N=8261\end{array}$} & \multicolumn{2}{|l|}{ Men } & \multicolumn{2}{|l|}{ Women } \\
\hline & & $\begin{array}{l}\text { Aged } \\
<60 \text { years } \\
n=2249\end{array}$ & $\begin{array}{l}\text { Aged } \\
\geq 60 \text { years } \\
n=3883\end{array}$ & $\begin{array}{l}\text { Aged } \\
<60 \text { years } \\
n=566\end{array}$ & $\begin{array}{l}\text { Aged } \\
\geq 60 \text { years } \\
n=1563\end{array}$ \\
\hline Smoking & $19 \%$ & $31 \%$ & $15 \%$ & $21 \%$ & $10 \%$ \\
\hline Persistent smoking & $55 \%$ & $54 \%$ & $54 \%$ & $59 \%$ & $54 \%$ \\
\hline $\begin{array}{l}\text { Persistent smokers not having been offered professional advice } \\
\text { to quit }\end{array}$ & $15 \%$ & $14 \%$ & $15 \%$ & $12 \%$ & $18 \%$ \\
\hline $\begin{array}{l}\text { Persistent smokers not having attempted to quit smoking since } \\
\text { hospital discharge }\end{array}$ & $77 \%$ & $76 \%$ & $79 \%$ & $73 \%$ & $77 \%$ \\
\hline $\begin{array}{l}\text { Persistent smokers not having the intention to quit within the } \\
\text { next six months }\end{array}$ & $53 \%$ & $49 \%$ & $58 \%$ & $57 \%$ & $56 \%$ \\
\hline Overweight and obesity & $82 \%$ & $84 \%$ & $81 \%$ & $83 \%$ & $80 \%$ \\
\hline Obesity & $38 \%$ & $38 \%$ & $33 \%$ & $51 \%$ & $44 \%$ \\
\hline Central obesity & $59 \%$ & $50 \%$ & $53 \%$ & $80 \%$ & $77 \%$ \\
\hline Obese patients never been told they are overweight & $24 \%$ & $24 \%$ & $25 \%$ & $23 \%$ & $24 \%$ \\
\hline $\begin{array}{l}\text { Obese patients not having attempted actively to lose weight in } \\
\text { last month }\end{array}$ & $50 \%$ & $47 \%$ & $52 \%$ & $45 \%$ & $54 \%$ \\
\hline $\begin{array}{l}\text { Obese patients not seriously considering weight loss in next } \\
\text { six months }\end{array}$ & $41 \%$ & $33 \%$ & $43 \%$ & $43 \%$ & $46 \%$ \\
\hline Obese patients not being aware of their weight target & $40 \%$ & $38 \%$ & $36 \%$ & $54 \%$ & $43 \%$ \\
\hline $\begin{array}{l}\text { Obese patients not having been advised to follow dietary } \\
\text { guidelines }\end{array}$ & $38 \%$ & $35 \%$ & $40 \%$ & $40 \%$ & $36 \%$ \\
\hline Regular physical activity $\geq 30$ min on average five times a week & $34 \%$ & $39 \%$ & $35 \%$ & $28 \%$ & $27 \%$ \\
\hline $\begin{array}{l}\text { Vigorous physical activity for } \geq 20 \text { min at least three times a } \\
\text { week }\end{array}$ & $16 \%$ & $21 \%$ & $16 \%$ & $16 \%$ & $10 \%$ \\
\hline Performing planned physical activity to increase physical fitness & $35 \%$ & $39 \%$ & $36 \%$ & $28 \%$ & $27 \%$ \\
\hline $\begin{array}{l}\text { Not performing planned physical activity and no intention to } \\
\text { do so in next six months }\end{array}$ & $42 \%$ & $33 \%$ & $43 \%$ & $42 \%$ & $51 \%$ \\
\hline $\begin{array}{l}\text { Not having received personal advice to do more general } \\
\text { everyday activities }\end{array}$ & $46 \%$ & $41 \%$ & $47 \%$ & $47 \%$ & $49 \%$ \\
\hline
\end{tabular}

Smoking: self-reported smoking or $>10$ ppm carbon monoxide in breath; persistent smoking: self-reported smoking or $>10$ ppm carbon monoxide in breath in patients reporting to have been smoking in the month prior to the index event; overweight: body mass index (BMI) $\geq 25$ to $<30 \mathrm{~kg} / \mathrm{m}^{2}$; obesity: BMI $\geq 30 \mathrm{~kg} / \mathrm{m}^{2}$; central obesity: waist circumference $\geq 88 \mathrm{~cm}$ for women and $\geq 102 \mathrm{~cm}$ for men.

(Figure 1). The prevalence of persistent smoking among those who smoked in the month prior to the coronary event was $55 \%$ and $53 \%$ intended to quit smoking within the next six months. Although $85 \%$ of persistent smokers had been offered professional advice to quit, only $23 \%$ tried to stop and only a small proportion $(5 \%)$ attended a smoking cessation clinic. Nicotine replacement therapy, bupropion and varenicline, were prescribed to a small minority: $7 \%, 1 \%$ and $2 \%$ of these patients respectively.

Overall, $44 \%$ of patients were overweight and $38 \%$ were obese. The prevalence of central obesity was $59 \%$, markedly higher in women than in men. One in four obese patients reported never being told they were overweight and $23 \%$ reported not having had a weight measurement after hospital discharge. Only half of the obese patients had tried to lose weight while $59 \%$ were considering losing weight in the next six months. Thirty-eight per cent of obese and $40 \%$ of centrally obese patients had not obtained dietary guidelines and were not aware of their weight target.

Two-thirds $(66 \%)$ of patients (men $63 \%$; women $73 \%, p<0.0001)$ were not achieving the defined physical activity target. Vigorous activities were taken up by only $16 \%$. Fifty-eight per cent of the patients intended to become more active. Almost half of the patients $(46 \%)$ did not recall having received personal advice on physical activity.

\section{Blood pressure, lipids and diabetes}

The management of blood pressure, LDL-C and selfreported diabetes is presented in Table 3. Overall, 95\% of patients were on blood pressure lowering drugs (beta- 


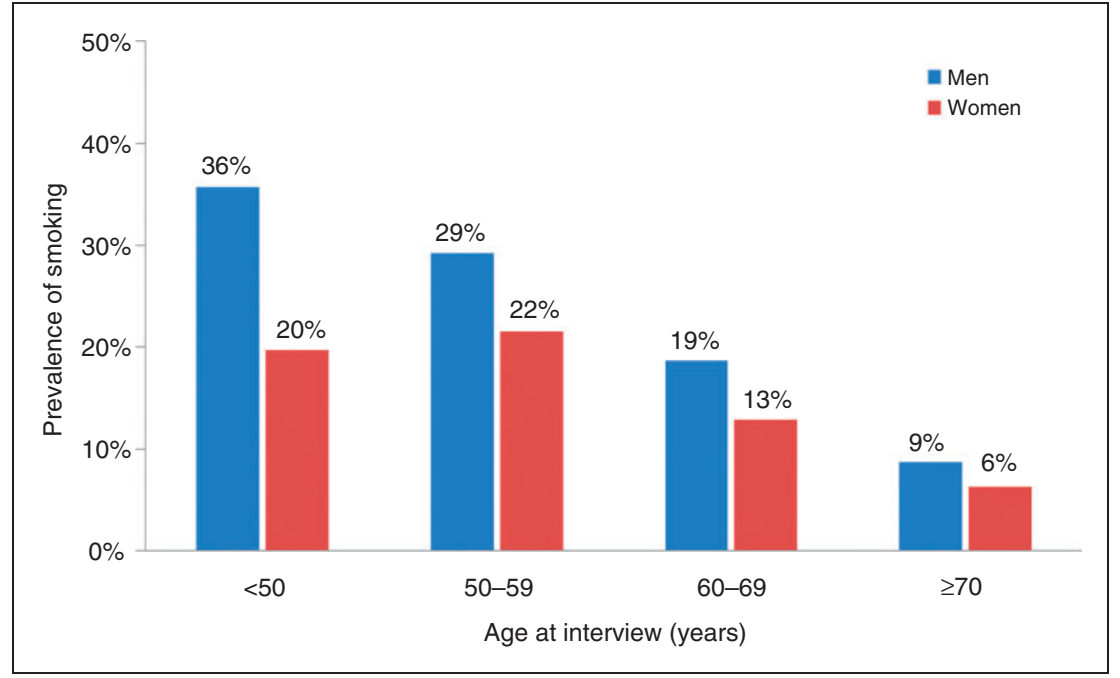

Figure I. Prevalence of smoking (\%) by age and gender at the time of the interview. Self-reported smoking or $>10 \mathrm{ppm}$ $\mathrm{CO}$ in breath.

Table 3. Cardiovascular risk factor management at the time of interview.

\begin{tabular}{|c|c|c|c|c|c|}
\hline \multirow[b]{2}{*}{ Risk factor } & \multirow[b]{2}{*}{$\begin{array}{l}\text { All } \\
N=826 I\end{array}$} & \multicolumn{2}{|l|}{ Men } & \multicolumn{2}{|l|}{ Women } \\
\hline & & $\begin{array}{l}\text { Aged } \\
<60 \text { years } \\
n=2249\end{array}$ & $\begin{array}{l}\text { Aged } \\
\geq 60 \text { years } \\
n=3883\end{array}$ & $\begin{array}{l}\text { Aged } \\
<60 \text { years } \\
n=566\end{array}$ & $\begin{array}{l}\text { Aged } \\
\geq 60 \text { years } \\
n=1563\end{array}$ \\
\hline Systolic/diastolic blood pressure $\geq 130 / 80 \mathrm{mmHg}$ & $71 \%$ & $68 \%$ & $74 \%$ & $65 \%$ & $72 \%$ \\
\hline $\begin{array}{l}\text { Systolic/diastolic blood pressure } \geq 140 / 90 \mathrm{mmHg}(\geq 140 / 85 \text { if } \\
\text { diabetes) }\end{array}$ & $42 \%$ & $35 \%$ & $46 \%$ & $38 \%$ & $44 \%$ \\
\hline Systolic/diastolic blood pressure $\geq 160 / 100 \mathrm{mmHg}$ & $12 \%$ & $9 \%$ & $13 \%$ & $12 \%$ & $13 \%$ \\
\hline Using blood pressure lowering drugs & $95 \%$ & $93 \%$ & $96 \%$ & $94 \%$ & $97 \%$ \\
\hline Using drugs specifically to lower blood pressure & $78 \%$ & $69 \%$ & $80 \%$ & $78 \%$ & $85 \%$ \\
\hline $\begin{array}{l}\text { Raised blood pressure in patients using drugs specifically to lower } \\
\text { blood pressure }\end{array}$ & $46 \%$ & $40 \%$ & $50 \%$ & $44 \%$ & $48 \%$ \\
\hline Reporting $100 \%$ compliance with blood pressure lowering drugs & $76 \%$ & $79 \%$ & $71 \%$ & $74 \%$ & $79 \%$ \\
\hline $\begin{array}{l}\text { If blood pressure raised, never been told by a doctor they have high } \\
\text { blood pressure }\end{array}$ & $15 \%$ & $20 \%$ & $16 \%$ & $12 \%$ & $8 \%$ \\
\hline $\mathrm{LDL}-\mathrm{C} \geq 1.8 \mathrm{mmol} / \mathrm{L}$ & $71 \%$ & $71 \%$ & $67 \%$ & $79 \%$ & $77 \%$ \\
\hline $\mathrm{LDL}-\mathrm{C} \geq 2.5 \mathrm{mmol} / \mathrm{L}$ & $37 \%$ & $37 \%$ & $32 \%$ & $50 \%$ & $45 \%$ \\
\hline If LDL-C $\geq 2.5 \mathrm{mmol} / \mathrm{L}$, never been told they have high cholesterol & $29 \%$ & $34 \%$ & $29 \%$ & $30 \%$ & $18 \%$ \\
\hline Using lipid-lowering drugs & $84 \%$ & $85 \%$ & $86 \%$ & $76 \%$ & $82 \%$ \\
\hline Using high-intensity lipid-lowering drugs & $50 \%$ & $53 \%$ & $50 \%$ & $47 \%$ & $45 \%$ \\
\hline Reporting $100 \%$ compliance with lipid-lowering drugs & $81 \%$ & $71 \%$ & $74 \%$ & $78 \%$ & $82 \%$ \\
\hline $\mathrm{LDL}-\mathrm{C} \geq 1.8 \mathrm{mmol} / \mathrm{L}$ in patients using lipid-lowering drugs & $68 \%$ & $68 \%$ & $65 \%$ & $76 \%$ & $74 \%$ \\
\hline Self-reported previous diagnosis of diabetes & $29 \%$ & $22 \%$ & $32 \%$ & $29 \%$ & $35 \%$ \\
\hline Treatment of diabetes: diet & $57 \%$ & $54 \%$ & $55 \%$ & $60 \%$ & $61 \%$ \\
\hline Insulin & $32 \%$ & $26 \%$ & $30 \%$ & $46 \%$ & $37 \%$ \\
\hline Oral antidiabetic drugs & $74 \%$ & $77 \%$ & $75 \%$ & $65 \%$ & $70 \%$ \\
\hline In patients with known diabetes, $\mathrm{HbAlc} \geq 7.0 \%$ & $46 \%$ & $48 \%$ & $41 \%$ & $65 \%$ & $47 \%$ \\
\hline
\end{tabular}

LDL-C: low-density lipoprotein cholesterol; HbAIc: glycated haemoglobin 
blockers, angiotensin-converting enzyme (ACE) inhibitors, angiotensin receptor blockers (ARBs), renin inhibitors, calcium-channel blockers, diuretics or other antihypertensives) and $78 \%$ of them confirmed they were on medication specifically to lower their blood pressure. The proportion with a blood pressure $\geq 130 / 80 \mathrm{mmHg}$ was $71 \%$ while $42 \%$ had a blood pressure of $\geq 140 / 90(\geq 140 / 85 \mathrm{mmHg}$ if diabetic) and $12 \%$ $\geq 160 / 100 \mathrm{mmHg}$. Fifteen per cent of patients with a blood pressure $\geq 140 / 90 \mathrm{mmHg}(\geq 140 / 85 \mathrm{mmHg}$ if diabetic) had never been told they had high blood pressure. Of patients prescribed drugs to lower their blood pressure $54 \%$ were at, or below, their recommended blood pressure target and $76 \%$ reported complete adherence with the intake of their blood pressure lowering drugs.

The proportion of patients with a $L D L-C$ level $\geq 1.8 \mathrm{mmol} / \mathrm{L}(\geq 70 \mathrm{mg} / \mathrm{dL})$ was $71 \%$, and $37 \%$ of all patients had a LDL-C $\geq 2.5 \mathrm{mmol} / \mathrm{L}(\geq 100 \mathrm{mg} / \mathrm{dL})$. In those with a LDL-C $\geq 2.5 \mathrm{mmol} / \mathrm{L}(\geq 100 \mathrm{mg} / \mathrm{dL}) 29 \%$ had never been informed of raised cholesterol and $21 \%$ had not had a cholesterol measurement since hospital discharge. Lipid-lowering drugs were prescribed to $84 \%$. Eighty per cent were taking statins and $50 \%$ of those on lipid-lowering drugs were taking high-intensity lipid-lowering drugs, or drug combinations, that may reduce LDL-C by $>50 \%$. Among patients on lipid-lowering drugs $32 \%$ had the target level of LDL$\mathrm{C}<1.8 \mathrm{mmol} / \mathrm{L}(<70 \mathrm{mg} / \mathrm{dL})$, less so in women than in men $(p<0.0001)$. Of patients on lipid-lowering drugs $76 \%$ reported full prescription compliance.

Twenty-nine per cent of all patients reported they had diabetes. Management with diet, insulin and oral glucose lowering drugs was $57 \%, 32 \%$ and $74 \%$ respectively. A HbAlc $\geq 7.0 \%(53 \mathrm{mmol} / \mathrm{mol})$ was recorded in $46 \%$ of these patients. Sixteen per cent of patients with known diabetes had not had a glucose measurement after discharge.

Less than half of patients (46\%) were advised to participate in a cardiac rehabilitation programme and $69 \%$ of those advised attended at least half of the sessions; $32 \%$ of all patients.

\section{Use of cardioprotective drugs}

Antiplatelet medication was prescribed in $93 \%$ of patients, $81 \%$ were on beta-blockers and $75 \%$ on ACE inhibitors or ARBs.

\section{Relations between lifestyle and risk factors}

LDL-C was less well controlled among smokers than among non-smokers $(p=0.001)$. A higher proportion of smokers $(75 \%)$ had a LDL-C $\geq 1.8 \mathrm{mmol} / \mathrm{L}$ $(\geq 70 \mathrm{mg} / \mathrm{dL})$ compared with non-smokers $(69 \%$, $p<0.0001)$. Overweight and obesity were associated with raised blood pressure and poorly controlled diabetes (Figures 2 and 3). There was a higher proportion with raised blood pressure with increasing BMI in both genders $(p<0.0001)$. Obesity was also associated with an elevated $\mathrm{HbA} 1 \mathrm{c}$ in patients with diabetes $(p=0.001)$.

\section{Discussion}

The EUROASPIRE V survey revealed that a majority of coronary patients failed to achieve the lifestyle,

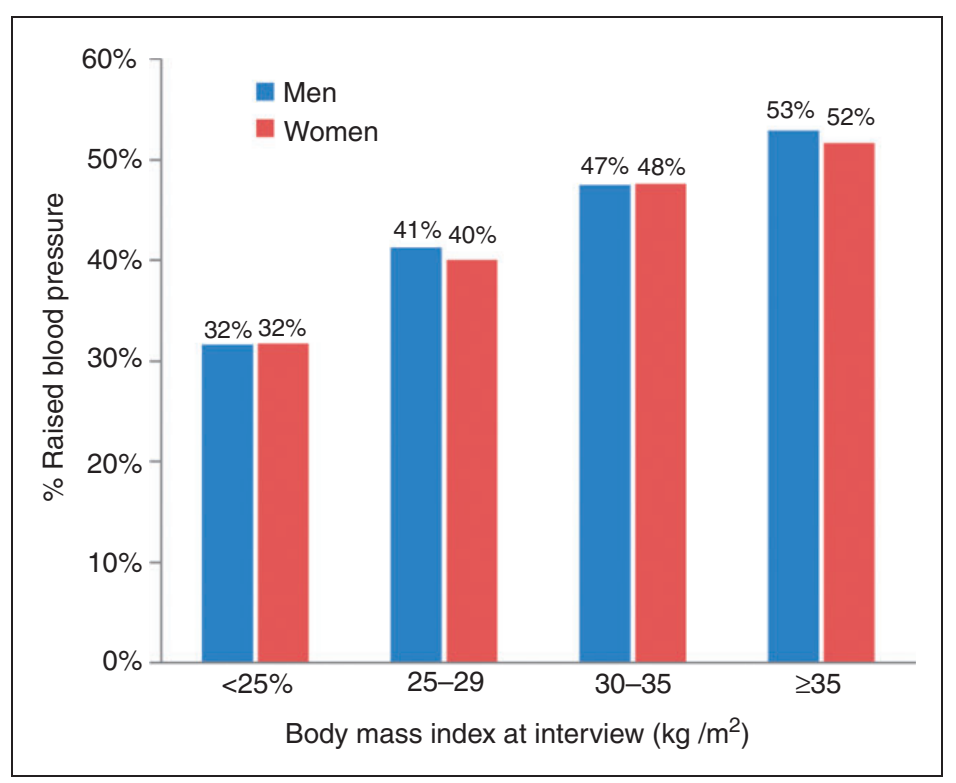

Figure 2. Prevalence of raised blood pressure (\%) in men and women by body mass index level. Raised blood pressure: blood pressure $\geq 140 / 90 \mathrm{mmHg}$ ( $\geq 140 / 85 \mathrm{mmHg}$ in patients with diabetes mellitus). 


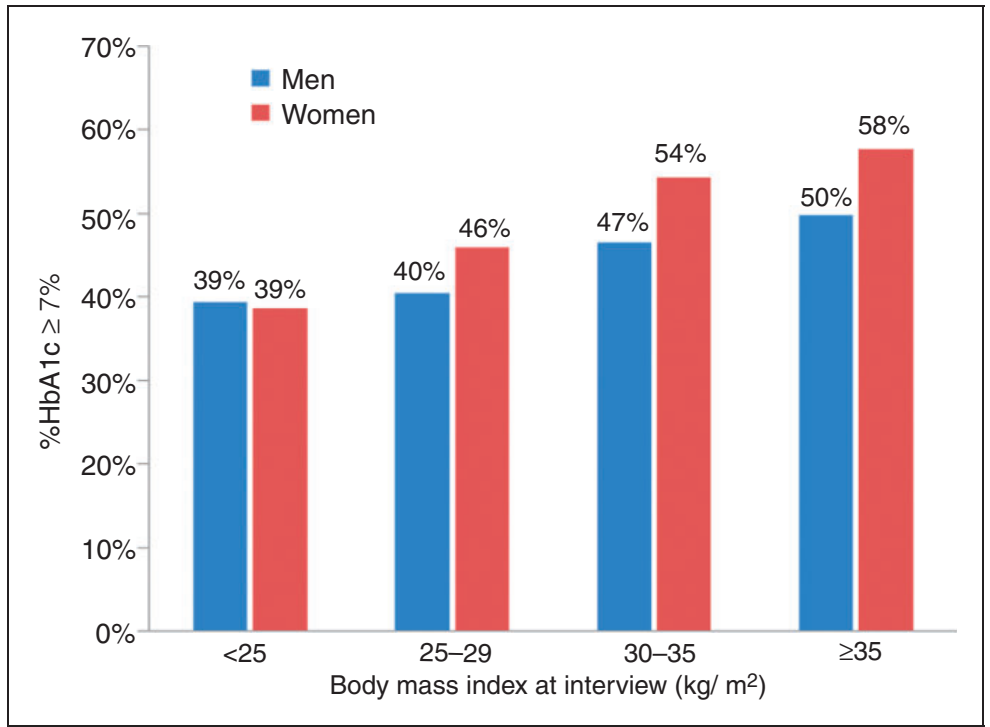

Figure 3. Prevalence of glycated haemoglobin $(\mathrm{HbAlc}) \geq 7.0 \%(\%)$ in male and female patients with known diabetes by body mass index level.

blood pressure, lipid and glycaemic targets of the 2016 JES guidelines on CVD prevention, and unhealthy lifestyles had an adverse impact on risk factor control in spite of a high use of cardioprotective medications.

The prevalence of smoking is a major challenge especially in patients $<50$ years, where $56 \%$ of men and $46 \%$ of women were persistent smokers. Smoking cessation after a myocardial infarction is very effective for secondary prevention. ${ }^{22,23}$ Despite compelling evidence smoking cessation strategies were poorly implemented. Only half of persistent smokers had an intention to quit smoking, which without behavioural support, including pharmacotherapies, is a daunting challenge for many patients addicted to nicotine. If encouragement and motivation are insufficient drug therapies should be considered early, including nicotine replacement therapies whilst in hospital, followed by bupropion or varenicline. ${ }^{24}$ Pharmacotherapies to support smoking cessation are effective, safe and associated with significant reductions in re-hospitalization and all-cause mortality. ${ }^{25,26}$

Weight reduction in overweight and obese people is recommended in order to reduce blood pressure, LDL$\mathrm{C}$ and the risk of type 2 diabetes and thus the risk of recurrent CVD. ${ }^{6}$ Obesity was associated with poorer blood pressure control, a higher prevalence of diabetes and poorer glycaemic control, illustrating the adverse impact of unhealthy lifestyles on risk factor control and the potential of lifestyle modification to further reduce CVD risk. Only two-fifths of obese patients reported trying to lose weight by changing their diet and increasing physical activity. Only half of the patients reported receiving advice to do more general daily physical activities. One in four of patients with a
BMI $\geq 30 \mathrm{~kg} / \mathrm{m}^{2}$ reported they had never been told they were overweight and less than half had tried to lose weight after their hospitalization. Yet, over half were considering losing weight in the next six months, illustrating a willingness to try.

Despite the high use of blood pressure lowering medications just over half of patients had achieved the recommended blood pressure goal and lipid control was unsatisfactory in a large proportion of patients, with more than two-thirds of patients above the target of LDL-cholesterol $<1.8 \mathrm{mmol} / \mathrm{L}(<70 \mathrm{mg} / \mathrm{dL})$. Prescription of lipid-lowering medication is recommended to all patients with documented CHD if not contraindicated. ${ }^{27}$ In EUROASPIRE V, four-fifths of patients were on lipid-lowering drugs, mainly statins, but the LDL-C was still poorly controlled, underlining the need for more intensive cholesterol management. Possible explanations could be that the initial doses of statins were too low or there was little or no up-titration of doses following treatment initiation, with only half of patients on high-intensity lipid-lowering drugs at interview.

Nearly one-third of patients had a history of diabetes, of whom just over half had a satisfactory glycaemic control.

The results of EUROASPIRE $\mathrm{V}$ are in accordance with earlier surveys of secondary prevention in Europe, the United States and other parts of the world. ${ }^{28-34}$ The results of Reduction of Atherothrombosis for Continued Health (REACH) Registry, ${ }^{28}$ the WHO study on Prevention of Recurrences of Myocardial Infarction and Stroke (WHO-PREMISE), ${ }^{29}$ STabilization of Atherosclerotic plaque By Initiation of darapLadIb 
TherapY (STABILITY) trial, ${ }^{30}$ the Prospective Urban Rural Epidemiology (PURE) study, ${ }^{31,32}$ the prospective observational LongitudinAl RegIstry oF patients with stable coronary arterY disease (CLARIFY) study ${ }^{33}$ and the Dyslipidemia International Study (DYSIS) ${ }^{34}$ demonstrated poor control of cardiovascular risk factors in patients with CHD.

There may be several reasons for the poor lifestyle adherence. To persuade patients to adapt to healthier habits needs skills in behavioural science and time enough to explain the importance. Moreover, and as shown by Pogosova et al., ${ }^{35}$ a substantial proportion of patients have anxiety and depression symptoms after coronary heart disease events, often left with unsatisfactory treatment. Thus, the receptivity to lifestyle advice may be less than optimal immediately after the coronary event and advice may have to be repeated or reinforced when the patient is in a better condition to accept such counselling. The scientific evidence on the importance of achieving healthier lifestyles for secondary prevention in people with CHD is strong. ${ }^{1-6}$ The importance of adherence to lifestyle changes was well documented in the Fifth Organisation to Assess Strategies in Acute Ischemic Syndromes (OASIS) trial. Persistent smokers who did not adhere to diet or exercise had a 3.8 -fold increased risk of repeated events compared with never smokers who modified their diet and activity pattern, and adherence to dietary and exercise advice was associated with a relative risk mortality reduction of $55 \% .{ }^{36}$ In the Randomized Evaluation of Secondary Prevention by Outpatient Nurse Specialists (RESPONSE) 2 trial the effect of comprehensive lifestyle programmes (targeting weight reduction, improved physical activity and smoking cessation) on top of usual care was evaluated in 824 patients after a recent acute coronary syndrome or coronary stenting. The primary outcome at 12 months was defined as improvement in $\geq 1$ qualifying lifestyle-related risk factor without deterioration in the other two. The combined outcome was reached more often in the intensive $(37 \%)$ than in the control group $(26 \%) .{ }^{37}$ In the EUROACTION trial of a nurse-led, multidisciplinary hospital programme for coronary patients there were significant improvements in diet (lower saturated fat, increased fruit and vegetables and increased oily fish consumption) and physical activity levels, with three times as many patients achieving the physical activity target in comparison with usual care. ${ }^{38}$

\section{Strengths and limitations}

To warrant the representativeness of EUROASPIRE V up to three geographical areas with a population greater than half a million people were selected within each country according to its size, and all hospitals serving that population identified, with a minimum of two within each geographical area. All centres that participated in the previous surveys were invited, and new centres were added from other geographical areas. The average interview rate was low at $56 \%$, reflecting falling participation in medical research generally, but also that some countries, due to data protection laws, restricted the invitation procedure by reducing the possibility to reinforce invitations, thereby limiting participation rate. This may introduce a potential bias but non-participants are more likely to have unhealthy lifestyles and poorer risk factor control and therefore the present findings are, if anything, probably underestimating the true status of preventive cardiology across Europe. A major strength of the EUROASPIRE surveys is that data are based on interviews and standardized methods and equipment, including central laboratory analyses, rather than data from medical records, which are often incomplete as regards risk factor recording. Therefore, our survey provides high quality comparative information on preventive cardiology practice in Europe.

\section{Conclusions}

The results of EUROASPIRE $\mathrm{V}$ reveal that among patients with CHD many have unhealthy lifestyles in terms of persistent smoking and weight related dietary factors, including sedentary behaviour. These unhealthy lifestyles adversely impact the control of major CVD risk factors such as hypertension, raised LDL-C and the prevalence of diabetes and its control. Despite the high use of cardioprotective drug therapies the majority of patients did not achieve their blood pressure, LDL-C and glucose targets.

Cardiovascular prevention requires a modern preventive cardiology programme with appropriate adaptation to medical and cultural settings in each country. All patients with CHD, or any other form of atherosclerotic disease, should be guaranteed access to such a programme delivered by interdisciplinary teams of healthcare professionals - nurses, dieticians, physiotherapists or physical activity specialists, psychologists and physicians - addressing all aspects of lifestyle, blood pressure, lipids and glucose management, and adherence to cardioprotective medications, in order to reduce their risk of recurrent cardiovascular events, improve quality of life and prolong survival.

\section{Acknowledgements}

Registry Executive Committee and Steering Committee of the EURObservational Research Programme (EORP). Data collection was conducted by the EORP department from the ESC by Emanuelle Fiorucci as Project Officer, Viviane Missiamenou and Florian Larras as Data Manager. The 
EUROASPIRE Study Group is grateful to the administrative staff, physicians, nurses and other personnel in the hospitals in which the survey was carried out and to all patients who participated in the surveys. All investigators are listed in the Supplemental Appendix 1. Statement of responsibility: the authors had full access to the data and took responsibility for its integrity. All authors have read and agreed to the written manuscript. Some of the results of this study were presented at the EUROPREVENT congress 2018 and ESC congress 2018.

\section{Author contribution}

KK contributed to conception and design, data acquisition, analysis and interpretation and drafted and critically revised the manuscript. GDB, DDB, LR, AH, DG, AM, PMV, CJ and DW contributed to conception and design, data acquisition, analysis and interpretation and critically revised the manuscript. AA, CA, JB, JB, ACC, RC, JC, KD, JD, DDS, JDS, MD, MD, VD, AE, ZF, DG, NG, PH, HHA, PJ, NL, SL, DL, SM, LM, DM, EM, RO, NP, ZR, SS, LT, $\mathrm{CT}$ and DV contributed to conception and design and data acquisition and critically revised the manuscript. All authors gave final approval and agreed to be accountable for all aspects of work ensuring integrity and accuracy.

\section{Declaration of conflicting interests}

The author(s) declared the following potential conflicts of interest with respect to the research, authorship and/or publication of this article: KK had grant support from the European Society of Cardiology for the submitted work. JB and RC were supported by grant No. 17-29520A provided by the Ministry of Health of the Czech Republic. PH and SS had research grants from the German Heart Foundation, the German Ministry of Research and Education, German Research Foundation, European Union, Charité, Berlin Chamber of Physicians, German Parkinson Society, University Hospital Würzburg, Robert-Koch-Institute, Federal Joint Committee (G-BA) within the Innovationfond, Charité-Universitätsmedizin Berlin (within MonDAFIS). GDB, DDB, LR, AH, DG, AM, PMV, CJ, $\mathrm{AA}, \mathrm{CA}, \mathrm{JB}, \mathrm{ACC}, \mathrm{JC}, \mathrm{KD}, \mathrm{JD}, \mathrm{DDS}, \mathrm{JDS}, \mathrm{MD}, \mathrm{MD}$, VD, AE, ZF, DG, NG, HHA, PJ, NL, SL, DL, SM, LM, DM, EM, RO, NP, ZR, LT, CT, DV, DW have no financial interests that are relevant to the submitted work.

\section{Funding}

The author(s) disclosed receipt of the following financial support for the research, authorship, and/or publication of this article: Since the start of EORP, the following companies have supported the programme: Amgen, Eli Lilly, Pfizer, Sanofi, Ferrer and Novo Nordisk. The sponsors of the EUROASPIRE surveys had no role in the design, data collection, data analysis, data interpretation, decision to publish, or writing the manuscript.

\section{References}

1. Pyörälä K, De Backer G, Graham I, et al. Prevention of coronary heart disease in clinical practice.
Recommendations of the Task Force of the European Society of Cardiology, European Atherosclerotic Society and European Society of Hypertension. Eur Heart J 1994; 15: 1300-1331.

2. Wood D, De Backer G, Faergeman D, et al. Prevention of coronary heart disease in clinical practice. Recommendations of the Second Joint Task Force of European and other Societies on coronary prevention. Eur Heart J 1998; 19: 1434-1503.

3. De Backer G, Ambrosioni E, Borch-Johnsen K, et al. European guidelines on cardiovascular disease prevention in clinical practice. Third Joint Task Force of European and other Societies on Cardiovascular Disease Prevention in Clinical Practice (constituted by representatives of eight societies and by invited experts). Eur $J$ Cardiovasc Prev Rehabil 2003; 10(Suppl .1): S1-S78.

4. Graham I, Atar D, Borch-Johnsen K, et al. European Guidelines on Cardiovascular Disease Prevention in Clinical Practice: Fourth Joint Task Force of the European Society of Cardiology and Other Societies on Cardiovascular Disease Prevention in Clinical Prevention in Clinical Practice (constituted by representatives of nine societies and by invited experts). Eur J Cardiovasc Prev Rehabil 2007; 14(Suppl. 2): S1-S113.

5. Perk J, De Backer G, Gohlke H, et al. European Guidelines on cardiovascular disease prevention in clinical practice (version 2012). The Fifth Joint Task Force of the European Society of Cardiology and Other Societies on Cardiovascular Disease Prevention in Clinical Practice (constituted by representatives of nine societies and by invited experts). Developed with the special contribution of the European Association for Cardiovascular Prevention \& Rehabilitation (EACPR). Eur Heart $J$ 2012; 33: 1635-1701.

6. Piepoli MF, Hoes AW, Agewall S, et al. 2016 European Guidelines on cardiovascular disease prevention in clinical practice. The Sixth Joint Task Force of the European Society of Cardiology and Other Societies on Cardiovascular Disease Prevention in Clinical Practice. Eur Heart $J$ 2016; 37: 2315-2381.

7. Wilkins E, Wilson L, Wickramasinghe K, et al. European cardiovascular disease statistics 2017. Brussels: European Heart Network.

8. EUROASPIRE Study Group. EUROASPIRE A European Society of Cardiology survey of secondary prevention of coronary heart disease: Principal results. Eur Heart J 1997; 18: 1569-1582.

9. EUROASPIRE Study Group. Lifestyle and risk factor management and use of drug therapies in coronary patients from 15 countries. Principal results from EUROASPIRE II. Euro Heart Survey Programme. Eur Heart J 2001; 22: 554-572.

10. EUROASPIRE Study Group. Clinical reality of coronary prevention guidelines: A comparison of EUROASPIRE I and II in nine countries. Lancet 2001; 357: 995-1001.

11. Kotseva K, Wood D, De Backer G, et al.; on behalf of EUROASPIRE III Study Group. EUROASPIRE III: A survey on the lifestyle, risk factors and use of cardioprotective drug therapies in coronary patients from 22 
European countries. Eur J Cardiovasc Prev Rehabil 2009; 16: 121-137.

12. Kotseva K, Wood D, De Backer G, et al.; on behalf of EUROASPIRE Study Group. Cardiovascular prevention guidelines in daily practice: A comparison of EUROASPIRE I, II, and III surveys in eight European countries. Lancet 2009; 373: 929-940.

13. Kotseva K, Wood D, De Bacquer D, et al.; on behalf of the EUROASPIRE Investigators. EUROASPIRE IV: A European Society of Cardiology survey on the lifestyle, risk factor and therapeutic management of coronary patients from twenty-four European countries. Eur $J$ Prev Cardiol 2016; 23: 636-648.

14. Kotseva K, De Bacquer D, Jennings C, et al.; on behalf of EUROASPIRE Investigators. Adverse lifestyle trends counter improvements in cardiovascular risk factor management in coronary patients: Results from three EUROASPIRE cross sectional surveys 1999-2013 of the European Society of Cardiology. JACC 2015; 66: 1633-1640.

15. Kotseva K, Wood D and De Bacquer D. Determinants of participation and risk factor control according to attendance in cardiac rehabilitation programmes in coronary patients in Europe: EUROASPIRE IV survey. Eur $J$ Prev Cardiol 2018; 25: 1242-1251.

16. Bartnik M, Ryden L, Ferrari R, et al. The prevalence of abnormal glucose regulation in patients with coronary artery disease across Europe. The Euro Heart Survey on diabetes and heart. Eur Heart J 2004; 25: 1880-1890.

17. Anselmino M, Bartni M, Öhrvik J, et al. The Euro Heart Survey on Diabetes and the Heart. Intern Diabetes Monitor 2010; 22: 1-9.

18. Middleton ET and Morice AH. Breath carbon monoxide as an indication of smoking habit. Chest 2000; 117: 758-763.

19. Lean MEJ, Han TS and Morrison CE. Waist circumference as a measure for indicating need for weight management. BMJ 1995; 311: 158-161.

20. Friedewald WT, Levy RI and Fredrickson DS. Estimation of the concentration of low-density lipoprotein cholesterol in plasma, without use of the preparative ultracentrifuge. Clin Chem 1972; 18: 499-502.

21. Segerhag E, Viveca Gyberg V, Ioannides K, et al. Accuracy of a simplified glucose measurement device The HemoCue ${ }^{\circledR}$ Glucose 201RT. Diabetes Technol Ther 2015; 17: 755-758.

22. Wilson K, Gibson N, Willan A, et al. Effect of smoking cessation on mortality after myocardial infarction: Metaanalysis of cohort studies. Arch Intern Med 2000; 160: 939-944.

23. Chritchley $\mathrm{J}$ and Capewell S. Mortality risk reduction associated with smoking cessation in patients with coronary heart disease: A systematic review. JAMA 2003; 290: 86-97.

24. Jennings C, Kotseva K, DeBacquer D, et al.; on behalf of EUROACTION PLUS Study Group. Effectiveness of a preventive cardiology programme for high CVDrisk persistent smokers: The EUROACTION PLUS Varenicline trial. Eur Heart $J$ 2014; 35: 1411-1120.
25. Cahill K, Stevens S, Perera R, et al. Pharmacological interventions for smoking cessation: An overview and network meta-analysis. Cochrane Database Syst Rev 2013; 5: CD009329.

26. Rigotti NA, Munafo MR and Stead LF. Smoking cessation interventions for hospitalized smokers: A systematic review. Arch Intern Med 2008; 168: 1950-1960.

27. Catapano AL, Graham I, De Backer G, et al. 2016 ESC/ EAS guidelines for the management of dyslipidaemias. Eur Heart J 2016; 37: 2999-3058.

28. Mehta RH, Bhatt DL, Steg PG, et al. REACH Registry Investigators. Modifiable risk factors control and its relationship with 1-year outcomes after coronary artery bypass surgery: Insights from the REACH registry. Eur Heart $J$ 2008; 29: 3052-3060.

29. Mendis S, Abegunde D, Yusuf S, et al.; WHO study on Prevention of REcurrences of Myocardial Infarction and StrokE (WHO-PREMISE). Bull World Health Organ 2005; 83: 820-829.

30. Vedin O, Hagstrom E, Stewart R, et al.; Secondary prevention and risk factor target achievement in a global, high-risk population with established coronary heart disease: Baseline results from the STABILITY study. Eur $J$ Prev Cardiology 2013; 20: 678-685.

31. Teo K, Lear S, Islam S, et al.; PURE Investigators. Prevalence of a healthy lifestyle among individuals with cardiovascular disease in high-, middle- and low-income countries: The Prospective Urban Rural Epidemiology (PURE) study. JAMA 2013; 309: 1613-1621.

32. Yusuf S, Islam S, Chow CK, et al.; Prospective Urban Rural Epidemiology (PURE) Study Investigators. Use of secondary prevention drugs for cardiovascular disease in the community in high-income, middle-income, and lowincome countries (the PURE Study): A prospective epidemiological survey. Lancet 2011; 378: 1231-1243.

33. Ferrari R, Ford I, Greenaw N, et al.; on behalf of the CLARIFY Registry Investigators. Geographical variations in the prevalence and management of cardiovascular risk factors in outpatients with CAD: Data from the contemporary CLARIFY registry. Eur J Prev Cardiol 2015; 22: 1056-1065.

34. Gitt AK, Drexel H, Feely J, et al.; on behalf of the DYSIS Investigators. Persistent lipid abnormalities in statin-treated patients and predictors of LDL-cholesterol goal achievement in clinical practice in Europe and Canada. Eur J Prev Cardiol 2011; 19: 221-230.

35. Pogosova N, Kotseva K, De Bacquer D, et al. Psychosocial risk factors in relation to other cardiovascular risk factors in coronary heart disease: Results from the EUROASPIRE IV survey. A registry from the European Society of Cardiology, on behalf of the EUROASPIRE Investigators. Eur J Prev Cardiol 2017; 24: $1371-1380$.

36. Chow CK, Jolly S, Rao-Melacini P, et al.; Association of diet, exercise, and smoking modification with risk of early cardiovascular events after acute coronary syndromes. Circulation 2010; 121: 750-758.

37. Minneboo M, Lachman S, Snaterse M, et al. on behalf of the RESPONSE-2 Study Group. Community-based lifestyle intervention in patients with coronary artery disease: 
The RESPONSE-2 Trial. J Am Coll Cardiol 2017; 70: 318-327.

38. Wood DA, Kotseva K, Connolly S, et al.; on behalf of EUROACTION Study Group. Nurse-coordinated multidisciplinary, family-based cardiovascular disease prevention programme (EUROACTION) for patients with coronary heart disease and asymptomatic individuals at high risk of cardiovascular disease: A paired, cluster-randomised controlled trial. Lancet 2008; 371: 1999-2012. 